\title{
Mediterranean Diet and Cardiovascular Risk
}

\author{
Javier Delgado-Lista, Ana I. Perez-Caballero, Pablo Perez-Martinez, \\ Antonio Garcia-Rios, Jose Lopez-Miranda and Francisco Perez-Jimenez \\ Unidad de Lipidos y Arteriosclerosis, IMIBIC/Hospital Universitario Reina Sofia, \\ Universidad de Cordoba, Ciber Fisiopatología Obesidad y Nutrición (CIBEROBN), \\ Instituto de Salud Carlos III, \\ Spain
}

\section{Introduction}

The Mediterranean diet is becoming a generalized recommended eating pattern worldwide, especially after epidemiological studies showing that adherence to this model is associated with a lower total mortality and cardiovascular diseases. Some of the conditions in which this dietary model has proven to be linked with a lower incidence are coronary events, stroke, hypertension, unfavorable blood glucose control, age cognitive decline or certain types of cancer (D. Giugliano \& Esposito, 2008; Kontou et al., 2011; Lopez-Miranda et al., 2010; Solfrizzi et al., 2011; Tangney et al., 2011; Willett, 2006). Although the underlying mechanisms by which this type of diet may exert its beneficial functions are far from being totally understood, current knowledge states that these are beyond the classical cardiovascular risk factors like lipids or the control or blood pressure, and involve, among others, inflammation, oxidative stress, coagulation and endothelial function.

One of the aspects to be taken into account when considering the effects of Mediterranean Diet is the heterogeneity of this concept, comprising different dietary patterns, slightly differing between the different countries in which this diet was originally consumed, because of local foodstuff preferences. The Mediterranean Diet includes a high consumption of food from plant origin (fruits, vegetables, nuts and grains), using olive oil (preferably extra virgin) as the main source of fat, used both as a cooking vehicle as for seasoning, although some other sources of monounsaturated fatty acids as the main dietary fat have been recently proposed. Mediterranean Diet preferred sources of protein are fish and poultry, while red meats are rarely consumed. Additionally, the use of sweets, pastry and dairy products are also of exceptional use. The use of milk and milk derived products, like yoghourt or cheese is moderated in most of the Mediterranean models, although with some country variations, with higher consumers, like the Greek dietary pattern. Finally, in some of the Mediterranean countries (like Spain, France and Italy) there is a common moderate consumption of red wine. These characteristics are summarized in figure 1.

The current interest in this type of food comes from the conjunction of a increasingly scientific evidence of the advantages of its consumption in different health aspects and its high palatability, which validates it for long use purposes, contrarily to other healthy alternatives with low palatability, which are difficult to maintain on a long outlook 
basis(Panunzio et al., 2011). Supporting the cited scientific evidences on cardiovascular risk, and validated by well designed works(Fuentes et al., 2001; Jansen et al., 2000; Kris-Etherton et al., 1993; Mata et al., 1992), the FDA authorized a health claim on olive oil on coronary heart disease (CFSAN/Office of Nutritional Products, 2004).

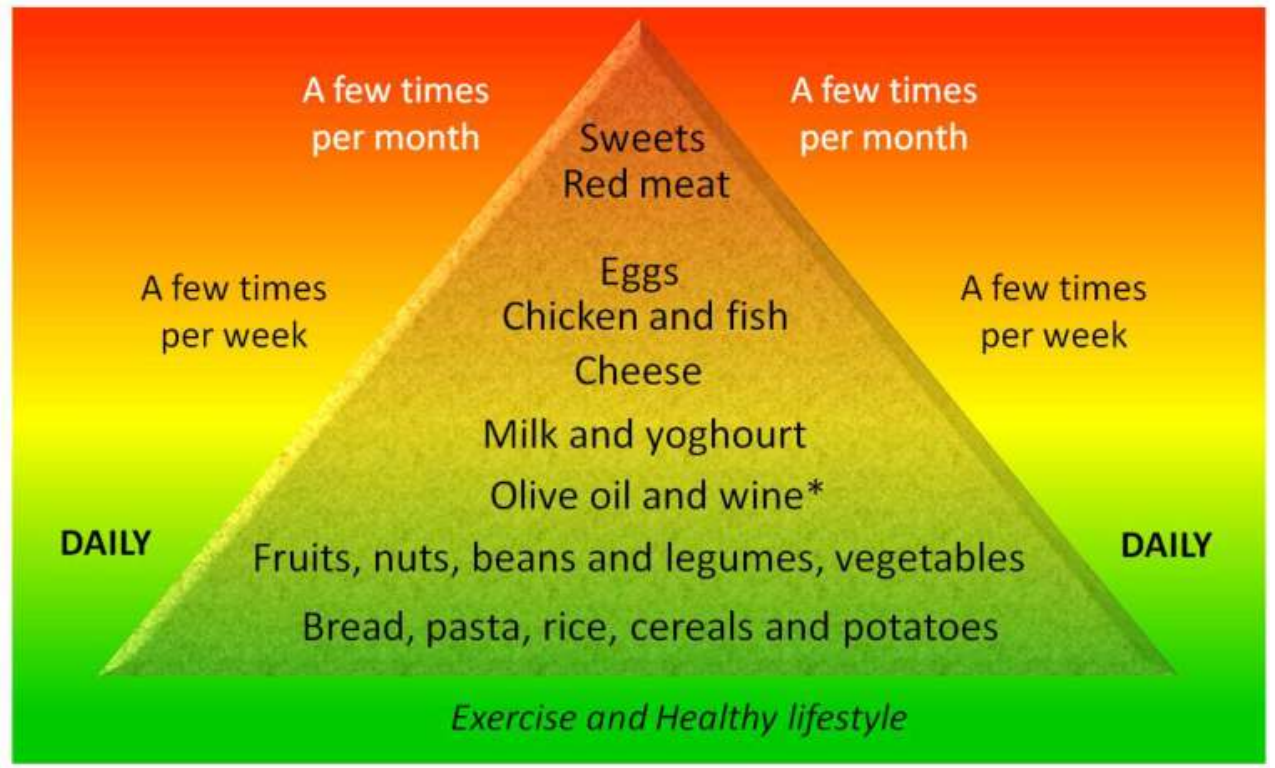

Fig. 1. Schematic representation of a Mediterranean diet pyramid. * Wine is only recommended in those adults that already consume it, or are willing to do it, and always with moderation (lower than $200 \mathrm{cc} /$ day). In no case wine consumption must be started only to comply with the Mediterranean diet.

As stated above, there is a plenty of conditions and physiological features where Mediterranean Diet has shown to be beneficial, from digestive tract motility to neurologic cognitive wellness in the aged persons, or the apparition of some types of cancer (D. Giugliano \& Esposito, 2008; Kontou et al., 2011; Lopez-Miranda et al., 2010; Solfrizzi et al., 2011; Tangney et al., 2011; Willett, 2006). However, we will only revise in the present document some of the evidences relating Mediterranean Diet and cardiovascular risk.

Assessing the modification of the cardiovascular risk by diet is a difficult task, specially having into account that cardiovascular risk assessment tools are not strictly uniform. Moreover, some of the increasingly accepted newer cardiovascular risk factors, like inflammation, thrombogenic state, postprandial lipemia, oxidative stress or endothelial function are not still included in the classical risk assessment tools. Finally, assessing the impact of the diet in different geographic locations has the risk of underestimate other diet related circumstances, like the fact of eating at home, eating out, the relative well-being or stress associated meal-time, or other interactions between eating and other behavior factors (like, for example meal-associated smoke consumption). In a recent article, it has been stated that the effects of Mediterranean Diet on total mortality increases when combined with 
other healthy lifestyle factors, like, nonsmoking, normal weight [BMI (in $\mathrm{kg} / \mathrm{m}(2)$ ): 18.5 to $<25$ ], and regular physical activity (van den Brandt, 2011). On the other hand, we cannot forget the interaction between the diet and the genetics of the population investigated, the so called nutrigenetics. The consumption of a nutrient may be more or less healthy in a given population depending on that population genetics(Allayee et al., 2009; Lairon et al., 2009; Lovegrove \& Gitau, 2008; Ordovas, 2006; Perez-Martinez et al., 2010a; Perez-Martinez et al., 2011b).

The purpose of this review is to present some evidence of studies which have already demonstrated the benefitial effects of the Mediterranean Diet in the different cardiovascular risk factors, and discuss the underlying mechanisms by which it exerts its effects. We will also review the different studies that link the consumption of this dietary model with a lower prevalence of cardiovascular disease.

\section{Mediterranean Diet and lipids}

The concentration of total cholesterol in plasma, as well as that of its fractions (HDL, LDL) is clearly related to cardiovascular risk, and hence they are included in the most used cardiovascular risk assessment tools, the Frammingham cardiovascular risk tables (N.C.E.P., 2001) and the European SCORE risk tool (HeartScore, 2003). While total cholesterol and LDL cholesterol are directly correlated to the risk, this relationship is reverse with HDL cholesterol. Triglycerides, which were not classically considered when assessing cardiovascular risk, have been recently identified as clear modifiers of cardiovascular risk, even independently of cholesterol, and an enlarged postprandial lipemia (which mainly involves triglyceride and triglyceride rich lipoproteins metabolism) has been identified as one of the major cardiovascular risk factors (Bayturan et al., 2010; Kolovou et al., 2011; Langsted et al., 2011; Lopez-Miranda et al., 2006; Patel et al., 2004; Sarwar et al., 2007; van Wijk et al., 2009; Varbo et al., 2011).

When considering the effects of the different types of diet on plasma lipids, studies have mainly centered on the effects of the fatty components of the diet studied in the lipid profile. For the studies dealing with Mediterranean Diet, this fact has driven to the study of the effects on lipids of olive oil as a food and of monounsaturated fatty acids as dietary fatty acids. With that scope it has been proved that lipid profile becomes healthier when Mediterranean diets rich in monounsaturated fats replace diets rich in saturated fatty acids rich diets, reducing LDL cholesterol, and the ratio total cholesterol/HDL.

The above effects were evaluated and corroborated by the FDA, when it approved the health claim on olive oil in 2004, authorizing the inclusion of the following sentence in the labeling of the olive oil bottles: Limited and not conclusive scientific evidence suggests that eating about two tablespoons (23 grams) of olive oil daily may reduce the risk of coronary heart disease due to the monounsaturated fat in olive oil. To achieve this possible benefit, olive oil is to replace a similar amount of saturated fat and not increase the total number of calories you eat in a day (CFSAN/Office of Nutritional Products, 2004).

Furthermore and complementing the favorable effects of olive oil, there has been extensively proven the beneficial effects of vegetables, fruits and pulse when replacing foods rich in saturated fatty acids, like butter, pork or red meat, reducing total cholesterol, triglycerides and LDL cholesterol (Bach-Faig et al., 2006; Lapointe et al., 2005; Mordente et al., 2011; 
Pitsavos et al., 2005; Tripoli et al., 2005; Visioli \& Galli, 1998; Yubero-Serrano et al., 2011). In addition, LDL resistance to oxidation is augmented when Mediterranean Diet rich in Olive Oil replaces diets rich in saturated fats. It is known that oxidation of LDL cholesterol is a key factor in the development of the atherosclerosis, promoting the formation of foam cells in the sub-endothelial space of the vascular wall. The underlying cause of this latter effect seems to be a combination of the monounsaturated fatty acids from olive oil, the antioxidant power of the minor compounds present in virgin olive oil, like phenols, and the elevated antioxidant capacity of the fruits and vegetables. Furthermore, a recent report from the European Food Safety Authority (EFSA) supports the effects of virgin olive oil phenols on LDL oxidation(EFSA, 2011). Lycopene, a carotenoid abundant in the tomato also deserves a mention, by its biochemical functions including acting as antioxidant scavenger, hypolipaemic agent, or inhibitor of pro-inflammatory and pro-thrombotic factors(Mordente et al., 2011). Additionally, resveratrol, a natural antioxidant present in red wine seems to play a role in this antioxidant effect on LDL cholesterol(Mukamal \& Rimm, 2008).

\section{Mediterranean Diet and blood pressure}

The influence of diet on blood pressure is well established. Diets rich in vegetables, like Mediterranean diet, reduce systolic and diastolic blood pressure (Alonso et al., 2006; Gillingham et al., 2011; Masala et al., 2008). These effects have been directly assessed in Mediterranean diet, and again they seem to be due to a combination of the favorable effects of olive oil, vegetables and fish (Alonso et al., 2004; Bondia-Pons et al., 2007; Din et al., 2004; Esposito et al., 2004; Fito et al., 2005; Gillingham et al., 2011; Masala et al., 2008; Perona et al., 2004). In fact, and supporting that the effect of olive oil is independent of the population studied or the dietary pattern, a north-european cohort who consumed olive oil as a part of their habitual diet reduced their blood pressure when switching their main fat source to olive oil(Bondia-Pons et al., 2007). A recent review summarized all the current information on the effects of monounsaturated fatty acids in blood pressure. In overall of the 16 studies analyzed, the authors reported that strong support can be obtained from clinical trials of the blood pressure lowering effects of MUFA rich diets in both normotensive and hypertensive individuals (Gillingham et al., 2011).

Not only the nutrient intake, but also the fiber content influences blood pressure. When adjusted by other possible confounders, the relative high percentage of the Mediterranean Diet is linked to a lower blood pressure (Alonso et al., 2006; Estruch et al., 2009). When studying the micronutrients responsible of these effects, the monounsaturated fats, the phenols from olive oil and vegetables and the n-3 fatty acids from fish seem to be implicated, as well as the relative low sodium levels achieved by vegetables compared to meat and the alcohol present in red wine, among others (Fito et al., 2005; Geleijnse et al., 2002; Masala et al., 2008; B. M. Rasmussen et al., 2006; Shah et al., 2007).

\section{Mediterranean Diet and smoking effects on cardiovascular disease}

Although the smoking habit is detrimental for the health in any dietary habit, the influence of the diet in the deleterious effects of smoking on health has not been widely studied. Epidemiological studies indicate that a high adherence to the Mediterranean Diet model is associated with a reduction of the risk conferred by the smoking habit (Haveman-Nies et al., 
2002; Mitrou et al., 2007). A recent work reviewed this topic in deep (Vardavas et al., 2011), and concludes, that, existing scientific literature indicates that the dietary intake of Mediterranean diet, can act as a positive effect modifier on the impact of smoking on cardiovascular health. When looking for underlying mechanisms, authors postulate two main hypothetical vias. Mediterranean Diet is rich in antioxidants. How we explained above, LDL resistance to oxidation in augmented when the person consumes Mediterranean Diet, and, thus, this person could be partially protected to the tobacco-induced LDL-oxidation. On the other hand, the increase of the HDL/total cholesterol provoked by the Mediterranean Diet could partially blunt the development of atherosclerosis caused by the smoking habit (Mitrou et al., 2007).

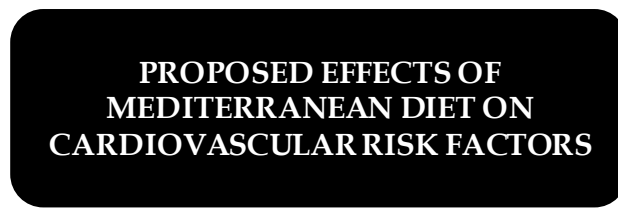

-Reduction of total cholesterol and LDL/HDL fraction

-Decrease of blood pressure (systolic, diastolic)

-Shortening of the postprandial lipemia

-Reduction the deleterious effect of smoking

- Reduction of oxidative stress and inflammation

-Decrease of clinical features of Metabolic Syndrome

-Better glycemic control and reduction of the pharmacological needs in Diabetes Mellitus

•Enhancement of endothelial function

-Less prothrombotic environment

Fig. 2. Proposed mechanisms for the healthy effects of Mediterranean diet on Cardiovascular Disease. 


\section{Mediterranean Diet and hemostasis}

Haemostatic system includes platelets and coagulation factors. It is devoted to maintain the optimal blood flow integrity, and to repair the vessels injuries. However, it has been firmly established that an unbalance of this system is a key factor in the development of atherosclerosis(Borissoff et al., 2011). The development of the plaque and its eventual rupture are favored by an increase in plasma of certain coagulation factors and platelet mediators. Diet can modulate the haemostatic equilibrium. Diets rich in fish, (especially blue fish) has an antiaggregant effect, mainly due to its content of n-3 fatty acids, which interferes with platelets metabolism(Renaud \& Lanzmann-Petithory, 2002; Seo et al., 2005). Furthermore, the direct effect of n-3 fatty acids reducing cardiovascular events and cardiovascular mortality has been proved both in epidemiological studies and clinical trials, although some recent studies failed to find such advantages(Filion et al., 2010; Harris et al., 2008; Lavie et al., 2009; Mente et al., 2009; Riediger et al., 2009). Currently, the AHA recommends two servings of blue fish a week for general population (to maintain a mean of $500 \mathrm{mg} / \mathrm{d}$ ), and $1 \mathrm{~g} / \mathrm{d}$ of marine omega-3 (EPA and DHA) in patients with coronary disease to lower cardiovascular risk, although safety issues due to the presence of harmful metals like mercury in large fish, like tuna or shark currently advices to take this recommendation with caution in pregnant women and little child (Kris-Etherton et al., 2002; Lichtenstein et al., 2006).

The same antiaggregant effect has been also find associated to the intake of olive oil, especially extra virgin olive oil, which has been justified by the presence of oleic acid and the minor components of virgin olive oil, like phenols. The underlying mechanisms for theses effects include tromboxane reduction, decrease of ADP reactivity and ATP release from platelets, decrease of platelet-activating factor (Antonopoulou et al., 2006; Karantonis et al., 2002; Karantonis et al., 2006; Perez-Jimenez et al., 2006; Singh et al., 2008; Sirtori et al., 1986; Smith et al., 2003). Effects of wine, a common element in certain countries consuming Mediterranean Diet have been also examined in some studies, but results are inconclusive. While its moderate consumption decreases some procoagulant species, like fibrinogen, and increase the natural anticoagulant TPA, also increases some proinflammatory markers (ICAM-1, E-Selectin, interleukin-6), and even may lead to an increase in total platelet aggregation (Mezzano \& Leighton, 2003; Tozzi Ciancarelli et al., 2011). Hereby, more studies are needed to unveil its overall influence on haemostasis.

The effects of olive oil in haemostasis go beyond platelets, and influences directly the plasma concentration of several procoagulant substances, like FVII (Delgado-Lista et al., 2008; Junker et al., 2001a; Junker et al., 2001b; Mezzano \& Leighton, 2003; Mezzano et al., 2003; Smith et al., 2003; Temme et al., 1999; Turpeinen \& Mutanen, 1999; Williams, 2001), tissue factor (Bravo-Herrera et al., 2004), fibrinogen (Mezzano \& Leighton, 2003), PAI-1 factor (Avellone et al., 1998; Perez-Jimenez, 2005; Perez-Jimenez et al., 1999; Perez-Jimenez et al., 2002) or von Willebrand Factor (Perez-Jimenez et al., 1999; O. Rasmussen et al., 1994), reducing the thrombogenic state when compared to diets rich in saturated fatty acids. Interestingly, these features have been found both in the fasting state and in the postprandial state, and have been also found, although to a lesser extent, associated to the consumption of nuts, other well represented food of Mediterranean diet(Delgado-Lista et al., 2008). These and other evidences of the beneficial influence of components of the Mediterranean diet have been published elsewhere(Delgado-Lista et al., 2011a; Delgado- 
Lista et al., 2007; Lopez-Miranda et al., 2007; Mezzano et al., 2003; Mordente et al., 2011). In summary, there are clear evidences on the healthy effects of components of the Mediterranean Diet in reducing the procoagulant and proagreggant species that promote atherosclerosis and eventual coronary events. These foods include extra virgin olive oil, vegetables, nuts and blue fish, and are supported by organizations like the FDA and the AHA(CFSAN/Office of Nutritional Products, 2004; Kris-Etherton et al., 2002).

\section{Mediterranean Diet and endothelial function}

In the new concepts of atherogenesis, the endothelial cells play a pivotal role in controlling the first steps and the final events of atherothombosis. The proper function of the vascular endothelium is essential to maintain a correct vasodilatation, but also to correctly regulate the metabolism of many other players involved in the atherogenesis, like the inflammatory cells, or the platelets. Meals rich in olive oil have a favorable effect on the postprandial vasomotor function of the endothelium, enhancing the vasodilator capacity during this phase, compared to meals rich in saturated fats, but also affect favorably other circulating markers of endothelial function. These effects are carried out, at least partly, by the minor compounds of virgin olive oil (Fuentes et al., 2008; Fuentes et al., 2001; Perez-Jimenez et al., 1999; Perez-Martinez et al., 2010c; Rallidis et al., 2009; Ruano et al., 2005), and may be also mediated by a lesser activation of leukocytes, a lower inflammation, and a higher bioavailability of nitric oxide (Carluccio et al., 2007; Covas, 2007; Davis et al., 2007; Fuentes et al., 2008; Leighton \& Urquiaga, 2007; Perez-Jimenez et al., 1999; Perez-Jimenez et al., 2007; Perez-Martinez et al., 2010b; Perona et al., 2006; Schini-Kerth et al., 2010; Serra-Majem et al., 2006; Visioli et al., 2005). Apart from olive oil, other important players in the effects of Mediterranean diet on endothelial function are nuts, fish and vegetables, all contributing to the wellbeing of this organ by promoting a lower proinflammatory, prooxidant environment(Estruch, 2010; Harris et al., 2003; Mena et al., 2009; Nadtochiy \& Redman, 2011; Papoutsi et al., 2008). Furthermore, it has been recently shown that people following Mediterranean Diet improve the regenerative capacity of the endothelium(Marin et al., 2011) and that elderly persons may partially blunt the oxidative processes associated to aging by adhering to Mediterranean diet, especially when combined with a rich antioxidant environment(Gutierrez-Mariscal et al., 2011).

\section{Mediterranean Diet, obesity, metabolic syndrome and type 2 diabetes mellitus}

The burden of a epidemic of obesity in modern countries has arisen the importance in public health strategies to search for dietary models reducing the incidence of obesity, and the related metabolic syndrome and type 2 diabetes mellitus, these two latter conditions characterized by a high cardiovascular risk.

Mediterranean Diet is an effective model to replace saturated fat rich diets, when looking for a healthy model to recommend to these persons. In fact, adherence to Mediterranean diet is inversely associated with the clustering of diabetes mellitus, obesity, hypertension and hypercholesterolemia (Sanchez-Tainta et al., 2008). Obesity rates are inversely associated with adherence to the Mediterranean diet on several observational cohorts (Beunza et al., 2010; Bullo et al., 2011; Mendez et al., 2006; Romaguera et al., 2009; Romaguera et al., 2010; 
Schroder et al., 2004; Trichopoulou et al., 2005), which has been explained by the higher satiating effect of olive oil rich meals(Schwartz et al., 2008). A recent meta-analysis including 16 randomized clinical trials found Mediterranean Diet as a useful tool to reduce obesity, especially when accompanied by other healthy habits(Esposito et al., 2011). In a similar way, an inverse correlation between the prevalence of Metabolic Syndrome and the adherence to Mediterranean Diet has been extensively reported(Panagiotakos et al., 2004; Tortosa et al., 2007), and some interventional studies have replicated these findings, showing that persons who are submitted to a Mediterranean type diet have a lower probability to show Metabolic Syndrome, even on ad libitum dietary regimen (Esposito et al., 2004; Salas-Salvado et al., 2008). These findings are related to the beneficial effects shown by diets rich in fruits, vegetables, grains, fish and low-fat dairy products, with the additional value of olive oil, which prevents the redistribution of body fat from peripheral to visceral adipose tissue, and partially enhances the postprandial lipid disturbances found in the metabolic syndrome patients(Esmaillzadeh et al., 2007; Jimenez-Gomez et al., 2010; Lutsey et al., 2008; Paniagua et al., 2007b; Pereira et al., 2005). A recent statement from the European Atherosclerosis Society recently recommended the Mediterranean Diet as the tool to combat the Metabolic Syndrome(Stock, 2011) by its capacity to reduce all clinical criteria of the disease, based on a recent meta-analysis that reported that adherence to Mediterranean Diet is related to a decrease in waist circumference by $42 \mathrm{~cm}$, increase in HDL cholesterol by $0.03 \mathrm{mmol} / \mathrm{l}$, decrease of triglycerides by $0.07 \mathrm{mmol} / 1$, decrease in blood pressure $(2.35 / 1.58 \mathrm{~mm} \mathrm{Hg})$, and decrease in blood glucose by $3.89 \mathrm{mg} / \mathrm{dL}$ (Kastorini et al., 2011)

With respect to type 2 diabetes, which is a frequent outcome in patients with sustained Metabolic Syndrome, it is reasonable to infer that Mediterranean Diet might prevent the development of diabetes or might improve the impaired metabolic status of the diabetic persons(D. Giugliano \& Esposito, 2008; Perez-Martinez et al., 2011a). In fact, large prospective studies have shown that adherence to Mediterranean Diet is inversely correlated with the risk of presenting type 2 diabetes mellitus (Martinez-Gonzalez et al., 2008; Mozaffarian et al., 2007), which has been eventually corroborated (de Koning et al., 2011; Delgado-Lista et al., 2011b; F. Giugliano et al., 2010). Some authors have published, indeed, that changing from a saturated fat rich diet to a Mediterranean Diet results in a decrease of glycated hemoglobin of around $0.3-2.0 \%$, which is close to the efficacy of some antidiabetic drugs, and allow to reduce pharmacological needs of these patients, which has also been reproduced when comparing Mediterranean Diet with a low fat diet (Elhayany et al., 2010; Itsiopoulos et al., 2010; Reisin, 2010). A recent randomized clinical trial showed that the risk of incident diabetes is reduced by more than 50\% when Mediterranean Diet (either with or without supplements of nuts) is compared with the low-fat group $(p<0.05)$ (SalasSalvado et al., 2011a). Some of the underlying mechanisms by which Mediterranean Diet improves the diabetes control are improving insulin sensitivity and blood lipids(Riccardi et al., 2004), improving postprandial lipemia(Lopez et al., 2008), improving glucose homeostasis (Paniagua et al., 2007a) or improve the beta-cell insulin secretion (RojoMartinez et al., 2006). Furthermore, and linking Mediterranean Diet, type 2 diabetes and cardiovascular risk, it has been recently published that Mediterranean Diet is associated with a better prognosis in total and cardiovascular mortality in type 2 diabetics(Hodge et al., 2010) All the relationships between the Mediterranean Diet, obesity and diabetes have been recently published (Perez-Martinez et al., 2011a; Salas-Salvado et al., 2011b). 


\section{Mediterranean Diet and epidemiological evidences on reduced cardiovascular risk}

The adherence to the Mediterranean Diet has been linked to a lower mortality by any cause and by cardiovascular disease in several observational studies, some of them including more than 350000 participants, like the NIH-AARP Diet and Health Study, where a high adherence to this dietary pattern resulted in an hazard ratio of 0.79 for all cause mortality, and of 0.83 for cardiovascular causes, which has been eventually corroborated (Mitrou et al., 2007; Serra-Majem et al., 2006). These data were included in an eventual meta-analysis (including more than 1.5 million persons), where it was stated that a rise of 2 points in a 9 points-scale of adherence to Mediterranean Diet was associated with a reduction of all cause mortality and cardiovascular mortality of about $10 \%$ (Sofi et al., 2008), which was eventually replicated in other meta-analysis(Sofi et al., 2010). In another meta-analysis, it has been state that a reduction of $5 \%$ of saturated by polyunsaturated fats result in a decrease of coronary risk (hazard ratio 0.87), while if this substitution was done by carbohydrates, there was no effect (Jakobsen et al., 2009). As stated previously, the Mediterranean Diet combines a high consumption of fish and a relative decrease in carbohydrates when compared with the low fat diets, which may combine the favored dietary patterns of the two above meta-analysis. Newer studies corroborate the inverse relationship between adherence to Mediterranean Diet and total mortality and cardiovascular death. High versus low adherence is accompanied was reported to be accompanied by a hazard ratio of 0.79 for total mortality, and 0.66 for cardiovascular death in a set of 40000 persons (Buckland et al., 2011). Furthermore, these effects are also evident in young cohorts. A recent report found a cardiovascular hazard ratio of 0.41 in 13000 young persons (mean age 38) with high versus low adherence to Mediterranean Diet(Martinez-Gonzalez et al., 2011)

Consequences of the non-fatal coronary event may also be limited by the Mediterranean Diet. A recent study has shown that left ventricle systolic dysfunction during hospitalization and the 2-y prognosis after an acute coronary syndrome are associated to the baseline diet. In this study, higher adherence to Mediterranean Diet was associated with less likelihood of developing left ventricle systolic dysfunction at hospitalization, less likelihood of remodeling (ejection fraction $<50 \%$ ) at 3 months of follow-up, and less likelihood of recurrent cardiovascular disease events during the $2 \mathrm{y}$ of follow-up(Chrysohoou et al., 2010)

Other of the underlying mechanisms for the reduced cardiovascular incidence observed in persons eating Mediterranean Diet is by promoting an adequate cardiac rhythm. Although preliminary, there are data supporting that adherence to the Mediterranean Diet is linked to a lower probability of developing atrial fibrillation, and to promote its spontaneous conversion (Mattioli, 2011; Mattioli et al., 2011), and that it improves cardiac autonomic function, as assessed by an increased heart rate variability(Dai et al., 2010)

Cerebrovascular disease is a very common form of presentation of cardiovascular disease, which has not been so studied as coronary heart disease, in relationship with its interaction with diet. A recent study analyzed the impact of Mediterranean Diet on magnetic resonance imaging-assessed cerebrovascular disease. In a random sample of 700 elderly subjects, medium and high adherence to Mediterranean Diet elicited a 22 and 36\% lower odds ratio for presenting evidence of infarcts on magnetic resonance imaging with respect to poor adherers (Scarmeas et al., 2011). In fact, adhering to nutritional features of Mediterranean Diet is more effective to act as secondary prevention for stroke than any single 
medication(Spence, 2010), even provoking the reversion of carotid atherosclerosis(Shai et al., 2010)

\section{Causal links between Mediterranean Diet and cardiovascular events: The need for randomized clinical trials}

With respect to clinical trials, two large dietary intervention trials with diet which used some features of the Mediterranean Diet were performed in Italy and France in the last years of the last century. The DART study evaluated the impact of three different dietary models (rich in fiber, low fat and rich in fish) in clinical outcomes of coronary patients. The use of two servings a week of fish was followed by a reduction of total mortality and cardiovascular death of about $30 \%$, but the effects of other components of the Mediterranean Diet were not assessed (Burr et al., 1989).

The Lyon study evaluated the effect of one so-called Mediterranean Diet on the clinical outcomes of coronary patients. After 4 years of follow up, those who used the Mediterranean Diet lowered the recurrence of cardiovascular events by 50-70\% (de Lorgeril et al., 1999). However, it must be said that the investigators used margarine rich in canola oil as their main fat source instead of olive oil, when this is not an usual component of the Mediterranean Diet. The reason for using such product was to provide high amounts of linolenic acid, a n-3 fatty acid of plant origin. Although the rest of the components of the diet that the author used matched the Mediterranean Diet characteristics, the use of the canola oil makes difficult to extrapolate the results to the traditional Mediterranean Diet.

The relative lack of clinical trials exploring cardiovascular outcome, using a complete Mediterranean Diet rich in Olive Oil, has opened the door for new initiatives. The PREDIMED study, close to conclude its follow up aims to compare the effects of a low fat diet with two Mediterranean Diet type diets (one of them enriched in nuts), on clinical cardiovascular endpoints of persons at risk of cardiovascular disease but without clinical disease (primary prevention). Until the final results are released, there have been published preliminary reports. The lower intake of olive oil was correlated with a thicker intima media thickness, a measure of the atherosclerosis in the carotid vessel, and a cardiovascular risk factor (Buil-Cosiales et al., 2008). Other risk factors previously suggested were also confirmed. Mediterranean Diet was followed by a decrease in glucose plasma levels, blood pressure and rises the proportion HDL/total cholesterol (Estruch et al., 2006).

The CordioPrev study aims to explore the effects of a low fat and a Mediterranean Diet in the recurrence of cardiovascular events and cardiovascular mortality in patients with coronary heart disease, exploring also multiple other endpoints, like incidence of cancer, lipids, glucose metabolism or age associated cognitive decline, after 5 years of follow up. This study is still in recruitment stage, and it may unravel the existence of causality in the relationship between Mediterranean Diet and lower recurrence of cardiovascular disease(CordioPrev, 2010).

These and other ongoing studies will help to ascertain if there is causality under the well stablished clinical associations between Mediterranean Diet and cardiovascular disease clinical endpoints. 


\section{Conclusions}

Mediterranean Diet has shown beneficial effects in multiple cardiovascular risk factors and underlying mechanisms of atherosclerosis, including a favorable lipid profile, a decrease of blood pressure, a shortening of the postprandial lipemia, a partial reduction in the harmful effects of smoking, a reduction of oxidative stress and inflammation, a reduction in the incidence and control of the clinical features of the Metabolic Syndrome, a better glycemic control, an enhancement of endothelial function, or the creation of a less prothrombotic environment (Figure 2). The results from observational and cohort studies link the high adherence to Mediterranean Diet with a lower total mortality and a decrease in cardiovascular events and cardiovascular mortality. Although it is not the scope of the present chapter, it has also been linked to several other healthy benefits, like a decrease in the incidence of certain types of tumors or a better cognitive function in aged persons.

The underlying mechanisms by which the Mediterranean Diet exerts its pleiotropic effects are difficult to discover, especially having into account that it is a flexible dietary pattern, with local differences depending on the geographical area in which it is studied. However, a combination of the healthy effects of its main components, like the use of Virgin Olive Oil and the high proportion of fruits and vegetables, grains and fish may be in the origin.

Meanwhile the large clinical trials designed to proof causality between Mediterranean Diet and cardiovascular disease publish their results, the effects of this dietary model on the cardiovascular risk factors and on the mechanisms of atherosclerosis, as well as the results from epidemiological studies allow us to infer that Mediterranean Diet may be an optimal dietary model to face the development of cardiovascular diseases.

\section{Acknowledgments}

Supported in part by research grants from the Spanish Ministry of Science and Innovation (AGL 2004-07907, AGL2006-01979, and AGL2009-12270 to J L-M, SAF07-62005 to F P-J and FIS PI10/01041 to P P-M, PI10/02412 to F P-J); Consejería de Economía, Innovación y Ciencia, Proyectos de Investigación de Excelencia, Junta de Andalucía (P06-CTS-01425 to J L-M, CTS5015 and AGR922 to F P-J); Consejería de Salud, Junta de Andalucía (06/128, 07/43, and PI0193/09 to J L-M, 06/129 to F P-J, 06/127 to C M-H, 0118/08 to F F-J, PI0252/09 to J D-L, and PI-0058/10 to P P-M); Fondo Europeo de Desarrollo Regional (FEDER). The CIBEROBN is an initiative of the Instituto de Salud Carlos III, Madrid, Spain.

\section{References}

Alonso, A., J. J. Beunza, M. Bes-Rastrollo, R. M. Pajares \& M. A. Martinez-Gonzalez (2006). "Vegetable protein and fiber from cereal are inversely associated with the risk of hypertension in a Spanish cohort." Arch Med Res 37 (6): 778-786.

Alonso, A., C. de la Fuente, A. M. Martin-Arnau, J. de Irala, J. A. Martinez \& M. A. MartinezGonzalez (2004). "Fruit and vegetable consumption is inversely associated with blood pressure in a Mediterranean population with a high vegetable-fat intake: the Seguimiento Universidad de Navarra (SUN) Study." Br J Nutr 92 (2): 311-319.

Allayee, H., N. Roth \& H. N. Hodis (2009). "Polyunsaturated fatty acids and cardiovascular disease: implications for nutrigenetics." J Nutrigenet Nutrigenomics 2 (3): 140-148. 
Antonopoulou, S., E. Fragopoulou, H. C. Karantonis, E. Mitsou, M. Sitara, J. Rementzis, A. Mourelatos, A. Ginis \& C. Phenekos (2006). "Effect of traditional Greek Mediterranean meals on platelet aggregation in normal subjects and in patients with type 2 diabetes mellitus." J Med Food 9 (3): 356-362.

Avellone, G., R. Cordova, L. Scalffidi \& G. Bompiani (1998). "Effects of Mediterranean diet on lipid, coagulative and fibrinolytic parameters in two randomly selected population samples in Western Sicily." Nutr Metab Cardiovasc Dis 8: 287-296.

Bach-Faig, A., D. Geleva, J. L. Carrasco, L. Ribas-Barba \& L. Serra-Majem (2006). "Evaluating associations between Mediterranean diet adherence indexes and biomarkers of diet and disease." Public Health Nutr 9 (8A): 1110-1117.

Bayturan, O., E. M. Tuzcu, A. Lavoie, T. Hu, K. Wolski, P. Schoenhagen, S. Kapadia, S. E. Nissen \& S. J. Nicholls (2010). "The metabolic syndrome, its component risk factors, and progression of coronary atherosclerosis." Arch Intern Med 170 (5): 478-484.

Beunza, J. J., E. Toledo, F. B. Hu, M. Bes-Rastrollo, M. Serrano-Martinez, A. SanchezVillegas, J. A. Martinez \& M. A. Martinez-Gonzalez (2010). "Adherence to the Mediterranean diet, long-term weight change, and incident overweight or obesity: the Seguimiento Universidad de Navarra (SUN) cohort." Am J Clin Nutr 92 (6): 1484-1493.

Bondia-Pons, I., H. Schroder, M. I. Covas, A. I. Castellote, J. Kaikkonen, H. E. Poulsen, A. V. Gaddi, A. Machowetz, H. Kiesewetter \& M. C. Lopez-Sabater (2007). "Moderate consumption of olive oil by healthy European men reduces systolic blood pressure in non-Mediterranean participants." J Nutr 137 (1): 84-87.

Borissoff, J. I., H. M. Spronk \& H. ten Cate (2011). "The hemostatic system as a modulator of atherosclerosis." N Engl J Med 364 (18): 1746-1760.

Bravo-Herrera, M. D., J. Lopez-Miranda, C. Marin, P. Gomez, M. J. Gomez, J. A. Moreno, P. Perez-Martinez, A. Blanco, Y. Jimenez-Gomez \& F. Perez-Jimenez (2004). "Tissue factor expression is decreased in monocytes obtained from blood during Mediterranean or high carbohydrate diets." Nutr Metab Cardiovasc Dis 14 (3): 128132.

Buckland, G., A. Agudo, N. Travier, J. Maria Huerta, L. Cirera, M. J. Tormo, C. Navarro, M. Dolores Chirlaque, C. Moreno-Iribas, E. Ardanaz, A. Barricarte, J. Etxeberria, P. Marin, J. Ramon Quiros, M. L. Redondo, N. Larranaga, P. Amiano, M. Dorronsoro, L. Arriola, M. Basterretxea, M. J. Sanchez, E. Molina \& C. A. Gonzalez (2011). "Adherence to the Mediterranean diet reduces mortality in the Spanish cohort of the European Prospective Investigation into Cancer and Nutrition (EPIC-Spain)." Br J Nutr: 1-11.

Buil-Cosiales, P., P. Irimia, N. Berrade, A. Garcia-Arellano, M. Riverol, M. Murie-Fernandez, E. Martinez-Vila, M. A. Martinez-Gonzalez \& M. Serrano-Martinez (2008). "Carotid intima-media thickness is inversely associated with olive oil consumption." Atherosclerosis 196 (2): 742-748.

Bullo, M., M. Garcia-Aloy, M. A. Martinez-Gonzalez, D. Corella, J. D. Fernandez-Ballart, M. Fiol, E. Gomez-Gracia, R. Estruch, M. Ortega-Calvo, S. Francisco, G. Flores-Mateo, L. Serra-Majem, X. Pinto, M. I. Covas, E. Ros, R. Lamuela-Raventos \& J. SalasSalvado (2011). "Association between a healthy lifestyle and general obesity and abdominal obesity in an elderly population at high cardiovascular risk." Prev Med. 
Burr, M. L., A. M. Fehily, J. F. Gilbert, S. Rogers, R. M. Holliday, P. M. Sweetnam, P. C. Elwood \& N. M. Deadman (1989). "Effects of changes in fat, fish, and fibre intakes on death and myocardial reinfarction: diet and reinfarction trial (DART)." Lancet 2 (8666): 757-761.

Carluccio, M. A., M. Massaro, E. Scoditti \& R. De Caterina (2007). "Vasculoprotective potential of olive oil components." Mol Nutr Food Res 51 (10): 1225-1234.

CFSAN/Office of Nutritional Products, L. a. D. S. (2004) "Letter Responding to Health Claim Petition dated August 28, 2003: Monounsaturated Fatty Acids from Olive Oil and Coronary Heart Disease (Docket No 2003Q-0559)."

http://www.cfsan.fda.gov/ dms/qhcolive.html\#ref.

CordioPrev (2010). "(www.cordioprev.org/en)."

Covas, M. I. (2007). "Olive oil and the cardiovascular system." Pharmacol Res 55 (3): 175-186.

Chrysohoou, C., D. B. Panagiotakos, P. Aggelopoulos, C. M. Kastorini, I. Kehagia, C. Pitsavos \& C. Stefanadis (2010). "The Mediterranean diet contributes to the preservation of left ventricular systolic function and to the long-term favorable prognosis of patients who have had an acute coronary event." Am J Clin Nutr 92 (1): 47-54.

Dai, J., R. Lampert, P. W. Wilson, J. Goldberg, T. R. Ziegler \& V. Vaccarino (2010). "Mediterranean dietary pattern is associated with improved cardiac autonomic function among middle-aged men: a twin study." Circ Cardiovasc Qual Outcomes 3 (4): 366-373.

Davis, N., S. Katz \& J. Wylie-Rosett (2007). "The effect of diet on endothelial function." Cardiol Rev 15 (2): 62-66.

de Koning, L., S. E. Chiuve, T. T. Fung, W. C. Willett, E. B. Rimm \& F. B. Hu (2011). "Dietquality scores and the risk of type 2 diabetes in men." Diabetes Care 34 (5): 11501156.

de Lorgeril, M., P. Salen, J. L. Martin, I. Monjaud, J. Delaye \& N. Mamelle (1999). "Mediterranean diet, traditional risk factors, and the rate of cardiovascular complications after myocardial infarction: final report of the Lyon Diet Heart Study." Circulation 99 (6): 779-785.

Delgado-Lista, J., A. Garcia-Rios, P. Perez-Martinez, J. Lopez-Miranda \& F. Perez-Jimenez (2011a). "Olive oil and haemostasis: platelet function, thrombogenesis and fibrinolysis." Curr Pharm Des 17 (8): 778-785.

Delgado-Lista, J., A. Garcia-Rios, P. Perez-Martinez, J. Solivera, E. M. Yubero-Serrano, F. Fuentes, L. D. Parnell, J. Shen, P. Gomez, Y. Jimenez-Gomez, M. J. Gomez-Luna, C. Marin, S. E. Belisle, F. Rodriguez-Cantalejo, S. N. Meydani, J. M. Ordovas, F. PerezJimenez \& J. Lopez-Miranda (2011b). "Interleukin 1B variant -1473G/C (rs1143623) influences triglyceride and interleukin 6 metabolism." J Clin Endocrinol Metab 96 (5): E816-820.

Delgado-Lista, J., J. Lopez-Miranda, B. Cortes, P. Perez-Martinez, A. Lozano, R. GomezLuna, P. Gomez, M. J. Gomez, J. Criado, F. Fuentes \& F. Perez-Jimenez (2008). "Chronic dietary fat intake modifies the postprandial response of hemostatic markers to a single fatty test meal." Am J Clin Nutr 87 (2): 317-322.

Delgado-Lista, J., J. Lopez-Miranda, P. Perez-Martinez, J. Ruano, F. Fuentes \& F. PerezJimenez (2007). "Olive Oil and Hemostasis." Current Nutrition \& Food Science 3 (1): 175-182. 
Din, J. N., D. E. Newby \& A. D. Flapan (2004). "Omega 3 fatty acids and cardiovascular disease--fishing for a natural treatment." Bmj 328 (7430): 30-35.

EFSA (2011). "Scientific Opinion on the substantiation of health claims related to polyphenols in olive and protection of LDL particles from oxidative damage (ID 1333, 1638, 1639, 1696, 2865), maintenance of normal blood HDL cholesterol concentrations (ID 1639), maintenance of normal blood pressure (ID 3781), "antiinflammatory properties" (ID 1882), "contributes to the upper respiratory tract health" (ID 3468), "can help to maintain a normal function of gastrointestinal tract" (3779), and "contributes to body defences against external agents" (ID 3467) pursuant to Article 13(1) of Regulation (EC) No 1924/2006." EFSA journal 9 (4): 2033-2058.

Elhayany, A., A. Lustman, R. Abel, J. Attal-Singer \& S. Vinker (2010). "A low carbohydrate Mediterranean diet improves cardiovascular risk factors and diabetes control among overweight patients with type 2 diabetes mellitus: a 1-year prospective randomized intervention study." Diabetes Obes Metab 12 (3): 204-209.

Esmaillzadeh, A., M. Kimiagar, Y. Mehrabi, L. Azadbakht, F. B. Hu \& W. C. Willett (2007). "Dietary patterns, insulin resistance, and prevalence of the metabolic syndrome in women." Am J Clin Nutr 85 (3): 910-918.

Esposito, K., C. M. Kastorini, D. B. Panagiotakos \& D. Giugliano (2011). "Mediterranean diet and weight loss: meta-analysis of randomized controlled trials." Metab Syndr Relat Disord 9 (1): 1-12.

Esposito, K., R. Marfella, M. Ciotola, C. Di Palo, F. Giugliano, G. Giugliano, M. D'Armiento, F. D'Andrea \& D. Giugliano (2004). "Effect of a mediterranean-style diet on endothelial dysfunction and markers of vascular inflammation in the metabolic syndrome: a randomized trial." JAMA 292 (12): 1440-1446.

Estruch, R. (2010). "Anti-inflammatory effects of the Mediterranean diet: the experience of the PREDIMED study." Proc Nutr Soc 69 (3): 333-340.

Estruch, R., M. A. Martinez-Gonzalez, D. Corella, J. Basora-Gallisa, V. Ruiz-Gutierrez, M. I. Covas, M. Fiol, E. Gomez-Gracia, M. C. Lopez-Sabater, R. Escoda, M. A. Pena, J. Diez-Espino, C. Lahoz, J. Lapetra, G. Saez \& E. Ros (2009). "Effects of dietary fiber intake on risk factors for cardiovascular disease in subjects at high risk." J Epidemiol Community Health.

Estruch, R., M. A. Martinez-Gonzalez, D. Corella, J. Salas-Salvado, V. Ruiz-Gutierrez, M. I. Covas, M. Fiol, E. Gomez-Gracia, M. C. Lopez-Sabater, E. Vinyoles, F. Aros, M. Conde, C. Lahoz, J. Lapetra, G. Saez \& E. Ros (2006). "Effects of a Mediterraneanstyle diet on cardiovascular risk factors: a randomized trial." Ann Intern Med 145 (1): 1-11.

Filion, K. B., F. El Khoury, M. Bielinski, I. Schiller, N. Dendukuri \& J. M. Brophy (2010). "Omega-3 fatty acids in high-risk cardiovascular patients: a meta-analysis of randomized controlled trials." BMC Cardiovasc Disord 10: 24.

Fito, M., M. Cladellas, R. de la Torre, J. Marti, M. Alcantara, M. Pujadas-Bastardes, J. Marrugat, J. Bruguera, M. C. Lopez-Sabater, J. Vila \& M. I. Covas (2005). "Antioxidant effect of virgin olive oil in patients with stable coronary heart disease: a randomized, crossover, controlled, clinical trial." Atherosclerosis 181 (1): 149-158.

Fuentes, F., J. Lopez-Miranda, P. Perez-Martinez, Y. Jimenez, C. Marin, P. Gomez, J. M. Fernandez, J. Caballero, J. Delgado-Lista \& F. Perez-Jimenez (2008). "Chronic effects 
of a high-fat diet enriched with virgin olive oil and a low-fat diet enriched with alpha-linolenic acid on postprandial endothelial function in healthy men." Br J Nutr 100 (1): 159-165.

Fuentes, F., J. Lopez-Miranda, E. Sanchez, F. Sanchez, J. Paez, E. Paz-Rojas, C. Marin, P. Gomez, J. Jimenez-Pereperez, J. M. Ordovas \& F. Perez-Jimenez (2001). "Mediterranean and low-fat diets improve endothelial function in hypercholesterolemic men." Ann Intern Med 134 (12): 1115-1119.

Gasparyan, A. Y., L. Ayvazyan, D. P. Mikhailidis \& G. D. Kitas (2011). "Mean platelet volume: a link between thrombosis and inflammation?" Curr Pharm Des 17 (1): 4758.

Geleijnse, J. M., E. J. Giltay, D. E. Grobbee, A. R. Donders \& F. J. Kok (2002). "Blood pressure response to fish oil supplementation: metaregression analysis of randomized trials." J Hypertens 20 (8): 1493-1499.

Gillingham, L. G., S. Harris-Janz \& P. J. Jones (2011). "Dietary monounsaturated fatty acids are protective against metabolic syndrome and cardiovascular disease risk factors." Lipids 46 (3): 209-228.

Giugliano, D. \& K. Esposito (2008). "Mediterranean diet and metabolic diseases." Curr Opin Lipidol 19 (1): 63-68.

Giugliano, F., M. I. Maiorino, G. Bellastella, R. Autorino, M. De Sio, D. Giugliano \& K. Esposito (2010). "Adherence to Mediterranean diet and erectile dysfunction in men with type 2 diabetes." J Sex Med 7 (5): 1911-1917.

Gutierrez-Mariscal, F. M., P. Perez-Martinez, J. Delgado-Lista, E. M. Yubero-Serrano, A. Camargo, N. Delgado-Casado, C. Cruz-Teno, M. Santos-Gonzalez, F. RodriguezCantalejo, J. P. Castano, J. M. Villalba-Montoro, F. Fuentes, F. Perez-Jimenez \& J. Lopez-Miranda (2011). "Mediterranean diet supplemented with coenzyme Q10 induces postprandial changes in p53 in response to oxidative DNA damage in elderly subjects." Age (Dordr).

Harris, W. S., P. M. Kris-Etherton \& K. A. Harris (2008). "Intakes of long-chain omega-3 fatty acid associated with reduced risk for death from coronary heart disease in healthy adults." Curr Atheroscler Rep 10 (6): 503-509.

Harris, W. S., Y. Park \& W. L. Isley (2003). "Cardiovascular disease and long-chain omega-3 fatty acids." Curr Opin Lipidol 14 (1): 9-14.

Haveman-Nies, A., L. P. de Groot, J. Burema, J. A. Cruz, M. Osler \& W. A. van Staveren (2002). "Dietary quality and lifestyle factors in relation to 10-year mortality in older Europeans: the SENECA study." Am J Epidemiol 156 (10): 962-968.

HeartScore (2003). "http:/ / www.heartscore.org."

Hodge, A. M., D. R. English, C. Itsiopoulos, K. O'Dea \& G. G. Giles (2010). "Does a Mediterranean diet reduce the mortality risk associated with diabetes: Evidence from the Melbourne Collaborative Cohort Study." Nutr Metab Cardiovasc Dis.

Itsiopoulos, C., L. Brazionis, M. Kaimakamis, M. Cameron, J. D. Best, K. O'Dea \& K. Rowley (2010). "Can the Mediterranean diet lower HbA1c in type 2 diabetes? Results from a randomized cross-over study." Nutr Metab Cardiovasc Dis.

Jakobsen, M. U., E. J. O'Reilly, B. L. Heitmann, M. A. Pereira, K. Balter, G. E. Fraser, U. Goldbourt, G. Hallmans, P. Knekt, S. Liu, P. Pietinen, D. Spiegelman, J. Stevens, J. Virtamo, W. C. Willett \& A. Ascherio (2009). "Major types of dietary fat and risk of 
coronary heart disease: a pooled analysis of 11 cohort studies." Am J Clin Nutr 89 (5): 1425-1432.

Jansen, S., J. Lopez-Miranda, P. Castro, F. Lopez-Segura, C. Marin, J. M. Ordovas, E. Paz, J. Jimenez-Pereperez, F. Fuentes \& F. Perez-Jimenez (2000). "Low-fat and highmonounsaturated fatty acid diets decrease plasma cholesterol ester transfer protein concentrations in young, healthy, normolipemic men." Am J Clin Nutr 72 (1): 36-41.

Jimenez-Gomez, Y., C. Marin, P. Peerez-Martinez, J. Hartwich, M. Malczewska-Malec, I. Golabek, B. Kiec-Wilk, C. Cruz-Teno, F. Rodriguez, P. Gomez, M. J. Gomez-Luna, C. Defoort, M. J. Gibney, F. Perez-Jimenez, H. M. Roche \& J. Lopez-Miranda (2010). "A low-fat, high-complex carbohydrate diet supplemented with long-chain (n-3) fatty acids alters the postprandial lipoprotein profile in patients with metabolic syndrome." J Nutr 140 (9): 1595-1601.

Junker, R., M. Kratz, M. Neufeld, M. Erren, J. R. Nofer, H. Schulte, U. Nowak-Gottl, G. Assmann \& U. Wahrburg (2001a). "Effects of diets containing olive oil, sunflower oil, or rapeseed oil on the hemostatic system." Thromb Haemost 85 (2): 280-286.

Junker, R., B. Pieke, H. Schulte, R. Nofer, M. Neufeld, G. Assmann \& U. Wahrburg (2001b). "Changes in hemostasis during treatment of hypertriglyceridemia with a diet rich in monounsaturated and n-3 polyunsaturated fatty acids in comparison with a lowfat diet." Thromb Res 101 (5): 355-366.

Karantonis, H. C., S. Antonopoulou \& C. A. Demopoulos (2002). "Antithrombotic lipid minor constituents from vegetable oils. Comparison between olive oils and others." J Agric Food Chem 50 (5): 1150-1160.

Karantonis, H. C., S. Antonopoulou, D. N. Perrea, D. P. Sokolis, S. E. Theocharis, N. Kavantzas, D. G. Iliopoulos \& C. A. Demopoulos (2006). "In vivo antiatherogenic properties of olive oil and its constituent lipid classes in hyperlipidemic rabbits." Nutr Metab Cardiovasc Dis 16 (3): 174-185.

Kastorini, C. M., H. J. Milionis, K. Esposito, D. Giugliano, J. A. Goudevenos \& D. B. Panagiotakos (2011). "The effect of Mediterranean diet on metabolic syndrome and its components: a meta-analysis of 50 studies and 534,906 individuals." J Am Coll Cardiol 57 (11): 1299-1313.

Kolovou, G. D., D. P. Mikhailidis, J. Kovar, D. Lairon, B. G. Nordestgaard, T. C. Ooi, P. Perez-Martinez, H. Bilianou, K. Anagnostopoulou \& G. Panotopoulos (2011). "Assessment and clinical relevance of non-fasting and postprandial triglycerides: an expert panel statement." Curr Vasc Pharmacol 9 (3): 258-270.

Kontou, N., T. Psaltopoulou, D. Panagiotakos, M. A. Dimopoulos \& A. Linos (2011). "The Mediterranean Diet in Cancer Prevention: A Review." J Med Food.

Kris-Etherton, P. M., J. Derr, D. C. Mitchell, V. A. Mustad, M. E. Russell, E. T. McDonnell, D. Salabsky \& T. A. Pearson (1993). "The role of fatty acid saturation on plasma lipids, lipoproteins, and apolipoproteins: I. Effects of whole food diets high in cocoa butter, olive oil, soybean oil, dairy butter, and milk chocolate on the plasma lipids of young men." Metabolism 42 (1): 121-129.

Kris-Etherton, P. M., W. S. Harris \& L. J. Appel (2002). "Fish consumption, fish oil, omega-3 fatty acids, and cardiovascular disease." Circulation 106 (21): 2747-2757.

Lairon, D., C. Defoort, J. C. Martin, M. J. Amiot-Carlin, M. Gastaldi \& R. Planells (2009). "Nutrigenetics: links between genetic background and response to Mediterraneantype diets." Public health nutrition 12 (9A): 1601-1606. 
Langsted, A., J. J. Freiberg, A. Tybjaerg-Hansen, P. Schnohr, G. B. Jensen \& B. G. Nordestgaard (2011). "Nonfasting cholesterol and triglycerides and association with risk of myocardial infarction and total mortality: the Copenhagen City Heart Study with 31 years of follow-up." J Intern Med 270 (1): 65-75.

Lapointe, A., J. Goulet, C. Couillard, B. Lamarche \& S. Lemieux (2005). "A nutritional intervention promoting the Mediterranean food pattern is associated with a decrease in circulating oxidized LDL particles in healthy women from the Quebec City metropolitan area." J Nutr 135 (3): 410-415.

Lavie, C. J., R. V. Milani, M. R. Mehra \& H. O. Ventura (2009). "Omega-3 polyunsaturated fatty acids and cardiovascular diseases." J Am Coll Cardiol 54 (7): 585-594.

Leighton, F. \& I. Urquiaga (2007). "Endothelial nitric oxide synthase as a mediator of the positive health effects of Mediterranean diets and wine against metabolic syndrome." World Rev Nutr Diet 97: 33-51.

Lichtenstein, A. H., L. J. Appel, M. Brands, M. Carnethon, S. Daniels, H. A. Franch, B. Franklin, P. Kris-Etherton, W. S. Harris, B. Howard, N. Karanja, M. Lefevre, L. Rudel, F. Sacks, L. Van Horn, M. Winston \& J. Wylie-Rosett (2006). "Diet and lifestyle recommendations revision 2006: a scientific statement from the American Heart Association Nutrition Committee." Circulation 114 (1): 82-96.

Lopez-Miranda, J., J. Delgado-Lista, P. Perez-Martinez, Y. Jimenez-Gomez, F. Fuentes, J. Ruano \& C. Marin (2007). "Olive oil and the haemostatic system." Mol Nutr Food Res 51 (10): 1249-1259.

Lopez-Miranda, J., F. Perez-Jimenez, E. Ros, R. De Caterina, L. Badimon, M. I. Covas, E. Escrich, J. M. Ordovas, F. Soriguer, R. Abia, C. A. de la Lastra, M. Battino, D. Corella, J. Chamorro-Quiros, J. Delgado-Lista, D. Giugliano, K. Esposito, R. Estruch, J. M. Fernandez-Real, J. J. Gaforio, C. La Vecchia, D. Lairon, F. LopezSegura, P. Mata, J. A. Menendez, F. J. Muriana, J. Osada, D. B. Panagiotakos, J. A. Paniagua, P. Perez-Martinez, J. Perona, M. A. Peinado, M. Pineda-Priego, H. E. Poulsen, J. L. Quiles, M. C. Ramirez-Tortosa, J. Ruano, L. Serra-Majem, R. Sola, M. Solanas, V. Solfrizzi, R. de la Torre-Fornell, A. Trichopoulou, M. Uceda, J. M. Villalba-Montoro, J. R. Villar-Ortiz, F. Visioli \& N. Yiannakouris (2010). "Olive oil and health: summary of the II international conference on olive oil and health consensus report, Jaen and Cordoba (Spain) 2008." Nutr Metab Cardiovasc Dis 20 (4): 284-294.

Lopez-Miranda, J., P. Perez-Martinez, C. Marin, J. A. Moreno, P. Gomez \& F. Perez-Jimenez (2006). "Postprandial lipoprotein metabolism, genes and risk of cardiovascular disease." Curr Opin Lipidol 17 (2): 132-138.

Lopez, S., B. Bermudez, Y. M. Pacheco, J. Villar, R. Abia \& F. J. Muriana (2008). "Distinctive postprandial modulation of beta cell function and insulin sensitivity by dietary fats: monounsaturated compared with saturated fatty acids." Am J Clin Nutr 88 (3): 638644.

Lovegrove, J. A. \& R. Gitau (2008). "Nutrigenetics and CVD: what does the future hold?" The Proceedings of the Nutrition Society 67 (2): 206-213.

Lutsey, P. L., L. M. Steffen \& J. Stevens (2008). "Dietary intake and the development of the metabolic syndrome: the Atherosclerosis Risk in Communities study." Circulation 117 (6): 754-761. 
Marin, C., R. Ramirez, J. Delgado-Lista, E. M. Yubero-Serrano, P. Perez-Martinez, J. Carracedo, A. Garcia-Rios, F. Rodriguez, F. M. Gutierrez-Mariscal, P. Gomez, F. Perez-Jimenez \& J. Lopez-Miranda (2011). "Mediterranean diet reduces endothelial damage and improves the regenerative capacity of endothelium." Am J Clin Nutr 93 (2): 267-274.

Martinez-Gonzalez, M. A., C. de la Fuente-Arrillaga, J. M. Nunez-Cordoba, F. J. BasterraGortari, J. J. Beunza, Z. Vazquez, S. Benito, A. Tortosa \& M. Bes-Rastrollo (2008). "Adherence to Mediterranean diet and risk of developing diabetes: prospective cohort study." Bmj 336 (7657): 1348-1351.

Martinez-Gonzalez, M. A., M. Garcia-Lopez, M. Bes-Rastrollo, E. Toledo, E. H. MartinezLapiscina, M. Delgado-Rodriguez, Z. Vazquez, S. Benito \& J. J. Beunza (2011). "Mediterranean diet and the incidence of cardiovascular disease: a Spanish cohort." Nutr Metab Cardiovasc Dis 21 (4): 237-244.

Masala, G., B. Bendinelli, D. Versari, C. Saieva, M. Ceroti, F. Santagiuliana, S. Caini, S. Salvini, F. Sera, S. Taddei, L. Ghiadoni \& D. Palli (2008). "Anthropometric and dietary determinants of blood pressure in over 7000 Mediterranean women: the European Prospective Investigation into Cancer and Nutrition-Florence cohort." J Hypertens 26 (11): 2112-2120.

Mata, P., J. A. Garrido, J. M. Ordovas, E. Blazquez, L. A. Alvarez-Sala, M. J. Rubio, R. Alonso \& M. de Oya (1992). "Effect of dietary monounsaturated fatty acids on plasma lipoproteins and apolipoproteins in women." Am J Clin Nutr 56 (1): 77-83.

Mattioli, A. V. (2011). "Lifestyle and atrial fibrillation." Expert Rev Cardiovasc Ther 9 (7): 895902.

Mattioli, A. V., C. Miloro, S. Pennella, P. Pedrazzi \& A. Farinetti (2011). "Adherence to Mediterranean diet and intake of antioxidants influence spontaneous conversion of atrial fibrillation." Nutr Metab Cardiovasc Dis.

Mena, M. P., E. Sacanella, M. Vazquez-Agell, M. Morales, M. Fito, R. Escoda, M. SerranoMartinez, J. Salas-Salvado, N. Benages, R. Casas, R. M. Lamuela-Raventos, F. Masanes, E. Ros \& R. Estruch (2009). "Inhibition of circulating immune cell activation: a molecular antiinflammatory effect of the Mediterranean diet." Am J Clin Nutr 89 (1): 248-256.

Mendez, M. A., B. M. Popkin, P. Jakszyn, A. Berenguer, M. J. Tormo, M. J. Sanchez, J. R. Quiros, G. Pera, C. Navarro, C. Martinez, N. Larranaga, M. Dorronsoro, M. D. Chirlaque, A. Barricarte, E. Ardanaz, P. Amiano, A. Agudo \& C. A. Gonzalez (2006). "Adherence to a Mediterranean diet is associated with reduced 3-year incidence of obesity." J Nutr 136 (11): 2934-2938.

Mente, A., L. de Koning, H. S. Shannon \& S. S. Anand (2009). "A systematic review of the evidence supporting a causal link between dietary factors and coronary heart disease." Arch Intern Med 169 (7): 659-669.

Mezzano, D. \& F. Leighton (2003). "Haemostatic cardiovascular risk factors: differential effects of red wine and diet on healthy young." Pathophysiol Haemost Thromb 33 (56): 472-478.

Mezzano, D., F. Leighton, P. Strobel, C. Martinez, G. Marshall, A. Cuevas, O. Castillo, O. Panes, B. Munoz, J. Rozowski \& J. Pereira (2003). "Mediterranean diet, but not red wine, is associated with beneficial changes in primary haemostasis." Eur J Clin Nutr 57 (3): 439-446. 
Mitrou, P. N., V. Kipnis, A. C. Thiebaut, J. Reedy, A. F. Subar, E. Wirfalt, A. Flood, T. Mouw, A. R. Hollenbeck, M. F. Leitzmann \& A. Schatzkin (2007). "Mediterranean dietary pattern and prediction of all-cause mortality in a US population: results from the NIH-AARP Diet and Health Study." Arch Intern Med 167 (22): 2461-2468.

Mordente, A., B. Guantario, E. Meucci, A. Silvestrini, E. Lombardi, G. E. Martorana, B. Giardina \& V. Bohm (2011). "Lycopene and cardiovascular diseases: an update." Curr Med Chem 18 (8): 1146-1163.

Mozaffarian, D., R. Marfisi, G. Levantesi, M. G. Silletta, L. Tavazzi, G. Tognoni, F. Valagussa \& R. Marchioli (2007). "Incidence of new-onset diabetes and impaired fasting glucose in patients with recent myocardial infarction and the effect of clinical and lifestyle risk factors." Lancet 370 (9588): 667-675.

Mukamal, K. J. \& E. B. Rimm (2008). "Alcohol consumption: risks and benefits." Curr Atheroscler Rep 10 (6): 536-543.

N.C.E.P. (2001). "http:/ / www.nhlbi.nih.gov/guidelines/cholesterol/atglance.pdf."

Nadtochiy, S. M. \& E. K. Redman (2011). "Mediterranean diet and cardioprotection: the role of nitrite, polyunsaturated fatty acids, and polyphenols." Nutrition 27 (7-8): 733-744.

Ordovas, J. M. (2006). "Nutrigenetics, plasma lipids, and cardiovascular risk." Journal of the American Dietetic Association 106 (7): 1074-1081; quiz 1083.

Panagiotakos, D. B., C. Pitsavos, C. Chrysohoou, J. Skoumas, D. Tousoulis, M. Toutouza, P. Toutouzas \& C. Stefanadis (2004). "Impact of lifestyle habits on the prevalence of the metabolic syndrome among Greek adults from the ATTICA study." Am Heart J 147 (1): 106-112.

Paniagua, J. A., A. G. de la Sacristana, E. Sanchez, I. Romero, A. Vidal-Puig, F. J. Berral, A. Escribano, M. J. Moyano, P. Perez-Martinez, J. Lopez-Miranda \& F. Perez-Jimenez (2007a). "A MUFA-rich diet improves posprandial glucose, lipid and GLP-1 responses in insulin-resistant subjects." J Am Coll Nutr 26 (5): 434-444.

Paniagua, J. A., A. Gallego de la Sacristana, I. Romero, A. Vidal-Puig, J. M. Latre, E. Sanchez, P. Perez-Martinez, J. Lopez-Miranda \& F. Perez-Jimenez (2007b). "Monounsaturated fat-rich diet prevents central body fat distribution and decreases postprandial adiponectin expression induced by a carbohydrate-rich diet in insulin-resistant subjects." Diabetes Care 30 (7): 1717-1723.

Panunzio, M. F., R. Caporizzi, A. Antoniciello, E. P. Cela, L. R. Ferguson \& P. D'Ambrosio (2011). "Randomized, controlled nutrition education trial promotes a Mediterranean diet and improves anthropometric, dietary, and metabolic parameters in adults." Ann Ig 23 (1): 13-25.

Papoutsi, Z., E. Kassi, I. Chinou, M. Halabalaki, L. A. Skaltsounis \& P. Moutsatsou (2008). "Walnut extract (Juglans regia L.) and its component ellagic acid exhibit antiinflammatory activity in human aorta endothelial cells and osteoblastic activity in the cell line KS483." Br J Nutr 99 (4): 715-722.

Patel, A., F. Barzi, K. Jamrozik, T. H. Lam, H. Ueshima, G. Whitlock \& M. Woodward (2004). "Serum triglycerides as a risk factor for cardiovascular diseases in the Asia-Pacific region." Circulation 110 (17): 2678-2686.

Pereira, M. A., A. I. Kartashov, C. B. Ebbeling, L. Van Horn, M. L. Slattery, D. R. Jacobs, Jr. \& D. S. Ludwig (2005). "Fast-food habits, weight gain, and insulin resistance (the CARDIA study): 15-year prospective analysis." Lancet 365 (9453): 36-42. 
Perez-Jimenez, F. (2005). "International conference on the healthy effect of virgin olive oil." Eur J Clin Invest 35 (7): 421-424.

Perez-Jimenez, F., P. Castro, J. Lopez-Miranda, E. Paz-Rojas, A. Blanco, F. Lopez-Segura, F. Velasco, C. Marin, F. Fuentes \& J. M. Ordovas (1999). "Circulating levels of endothelial function are modulated by dietary monounsaturated fat." Atherosclerosis 145 (2): 351-358.

Perez-Jimenez, F., J. D. Lista, P. Perez-Martinez, F. Lopez-Segura, F. Fuentes, B. Cortes, A. Lozano \& J. Lopez-Miranda (2006). "Olive oil and haemostasis: a review on its healthy effects." Public Health Nutr 9 (8A): 1083-1088.

Perez-Jimenez, F., J. Lopez-Miranda \& P. Mata (2002). "Protective effect of dietary monounsaturated fat on arteriosclerosis: beyond cholesterol." Atherosclerosis 163 (2): 385-398.

Perez-Jimenez, F., J. Ruano, P. Perez-Martinez, F. Lopez-Segura \& J. Lopez-Miranda (2007). "The influence of olive oil on human health: not a question of fat alone." Mol Nutr Food Res 51 (10): 1199-1208.

Perez-Martinez, P., J. Delgado-Lista, F. Perez-Jimenez \& J. Lopez-Miranda (2010a). "Update on genetics of postprandial lipemia." Atheroscler Suppl 11 (1): 39-43.

Perez-Martinez, P., J. M. Garcia-Quintana, E. M. Yubero-Serrano, I. Tasset-Cuevas, I. Tunez, A. Garcia-Rios, J. Delgado-Lista, C. Marin, F. Perez-Jimenez, H. M. Roche \& J. Lopez-Miranda (2010b). "Postprandial oxidative stress is modified by dietary fat: evidence from a human intervention study." Clin Sci (Lond) 119 (6): 251-261.

Perez-Martinez, P., A. Garcia-Rios, J. Delgado-Lista, F. Perez-Jimenez \& J. Lopez-Miranda (2011a). "Mediterranean diet rich in olive oil and obesity, metabolic syndrome and diabetes mellitus." Curr Pharm Des 17 (8): 769-777.

Perez-Martinez, P., A. Garcia-Rios, J. Delgado-Lista, F. Perez-Jimenez \& J. Lopez-Miranda (2011b). "Nutrigenetics of the postprandial lipoprotein metabolism: evidences from human intervention studies." Curr Vasc Pharmacol 9 (3): 287-291.

Perez-Martinez, P., M. Moreno-Conde, C. Cruz-Teno, J. Ruano, F. Fuentes, J. Delgado-Lista, A. Garcia-Rios, C. Marin, M. J. Gomez-Luna, F. Perez-Jimenez, H. M. Roche \& J. Lopez-Miranda (2010c). "Dietary fat differentially influences regulatory endothelial function during the postprandial state in patients with metabolic syndrome: from the LIPGENE study." Atherosclerosis 209 (2): 533-538.

Perona, J. S., R. Cabello-Moruno \& V. Ruiz-Gutierrez (2006). "The role of virgin olive oil components in the modulation of endothelial function." J Nutr Biochem 17 (7): 429445.

Perona, J. S., J. Canizares, E. Montero, J. M. Sanchez-Dominguez, A. Catala \& V. RuizGutierrez (2004). "Virgin olive oil reduces blood pressure in hypertensive elderly subjects." Clin Nutr 23 (5): 1113-1121.

Pitsavos, C., D. B. Panagiotakos, N. Tzima, C. Chrysohoou, M. Economou, A. Zampelas \& C. Stefanadis (2005). "Adherence to the Mediterranean diet is associated with total antioxidant capacity in healthy adults: the ATTICA study." Am J Clin Nutr 82 (3): 694-699.

Purnak, T., C. Efe, O. Yuksel, Y. Beyazit, E. Ozaslan \& E. Altiparmak (2011). "Mean platelet volume could be a promising biomarker to monitor dietary compliance in celiac disease." Ups J Med Sci 116 (3): 208-211. 
Rallidis, L. S., J. Lekakis, A. Kolomvotsou, A. Zampelas, G. Vamvakou, S. Efstathiou, G. Dimitriadis, S. A. Raptis \& D. T. Kremastinos (2009). "Close adherence to a Mediterranean diet improves endothelial function in subjects with abdominal obesity." Am J Clin Nutr 90 (2): 263-268.

Rasmussen, B. M., B. Vessby, M. Uusitupa, L. Berglund, E. Pedersen, G. Riccardi, A. A. Rivellese, L. Tapsell \& K. Hermansen (2006). "Effects of dietary saturated, monounsaturated, and n-3 fatty acids on blood pressure in healthy subjects." Am J Clin Nutr 83 (2): 221-226.

Rasmussen, O., C. Thomsen, J. Ingerslev \& K. Hermansen (1994). "Decrease in von Willebrand factor levels after a high-monounsaturated-fat diet in non-insulindependent diabetic subjects." Metabolism 43 (11): 1406-1409.

Reisin, E. (2010). "The benefit of the Mediterranean-style diet in patients with newly diagnosed diabetes." Curr Hypertens Rep 12 (2): 56-58.

Renaud, S. \& D. Lanzmann-Petithory (2002). "Dietary fats and coronary heart disease pathogenesis." Curr Atheroscler Rep 4 (6): 419-424.

Riccardi, G., R. Giacco \& A. A. Rivellese (2004). "Dietary fat, insulin sensitivity and the metabolic syndrome." Clin Nutr 23 (4): 447-456.

Riediger, N. D., R. A. Othman, M. Suh \& M. H. Moghadasian (2009). "A systemic review of the roles of n-3 fatty acids in health and disease." J Am Diet Assoc 109 (4): 668-679.

Rojo-Martinez, G., I. Esteva, M. S. Ruiz de Adana, J. M. Garcia-Almeida, F. Tinahones, F. Cardona, S. Morcillo, E. Garcia-Escobar, E. Garcia-Fuentes \& F. Soriguer (2006). "Dietary fatty acids and insulin secretion: a population-based study." Eur J Clin Nutr 60 (10): 1195-1200.

Romaguera, D., T. Norat, T. Mouw, A. M. May, C. Bamia, N. Slimani, N. Travier, H. Besson, J. Luan, N. Wareham, S. Rinaldi, E. Couto, F. Clavel-Chapelon, M. C. BoutronRuault, V. Cottet, D. Palli, C. Agnoli, S. Panico, R. Tumino, P. Vineis, A. Agudo, L. Rodriguez, M. J. Sanchez, P. Amiano, A. Barricarte, J. M. Huerta, T. J. Key, E. A. Spencer, H. B. Bueno-de-Mesquita, F. L. Buchner, P. Orfanos, A. Naska, A. Trichopoulou, S. Rohrmann, R. Kaaks, M. Bergmann, H. Boeing, I. Johansson, V. Hellstrom, J. Manjer, E. Wirfalt, M. Uhre Jacobsen, K. Overvad, A. Tjonneland, J. Halkjaer, E. Lund, T. Braaten, D. Engeset, A. Odysseos, E. Riboli \& P. H. Peeters (2009). "Adherence to the Mediterranean diet is associated with lower abdominal adiposity in European men and women." J Nutr 139 (9): 1728-1737.

Romaguera, D., T. Norat, A. C. Vergnaud, T. Mouw, A. M. May, A. Agudo, G. Buckland, N. Slimani, S. Rinaldi, E. Couto, F. Clavel-Chapelon, M. C. Boutron-Ruault, V. Cottet, S. Rohrmann, B. Teucher, M. Bergmann, H. Boeing, A. Tjonneland, J. Halkjaer, M. U. Jakobsen, C. C. Dahm, N. Travier, L. Rodriguez, M. J. Sanchez, P. Amiano, A. Barricarte, J. M. Huerta, J. Luan, N. Wareham, T. J. Key, E. A. Spencer, P. Orfanos, A. Naska, A. Trichopoulou, D. Palli, C. Agnoli, A. Mattiello, R. Tumino, P. Vineis, H. B. Bueno-de-Mesquita, F. L. Buchner, J. Manjer, E. Wirfalt, I. Johansson, V. Hellstrom, E. Lund, T. Braaten, D. Engeset, A. Odysseos, E. Riboli \& P. H. Peeters (2010). "Mediterranean dietary patterns and prospective weight change in participants of the EPIC-PANACEA project." Am J Clin Nutr 92 (4): 912-921.

Ruano, J., J. Lopez-Miranda, F. Fuentes, J. A. Moreno, C. Bellido, P. Perez-Martinez, A. Lozano, P. Gomez, Y. Jimenez \& F. Perez Jimenez (2005). "Phenolic content of 
virgin olive oil improves ischemic reactive hyperemia in hypercholesterolemic patients." J Am Coll Cardiol 46 (10): 1864-1868.

Salas-Salvado, J., M. Bullo, N. Babio, M. A. Martinez-Gonzalez, N. Ibarrola-Jurado, J. Basora, R. Estruch, M. I. Covas, D. Corella, F. Aros, V. Ruiz-Gutierrez \& E. Ros (2011a). "Reduction in the incidence of type 2 diabetes with the Mediterranean diet: results of the PREDIMED-Reus nutrition intervention randomized trial." Diabetes Care 34 (1): $14-19$.

Salas-Salvado, J., J. Fernandez-Ballart, E. Ros, M. A. Martinez-Gonzalez, M. Fito, R. Estruch, D. Corella, M. Fiol, E. Gomez-Gracia, F. Aros, G. Flores, J. Lapetra, R. LamuelaRaventos, V. Ruiz-Gutierrez, M. Bullo, J. Basora \& M. I. Covas (2008). "Effect of a Mediterranean diet supplemented with nuts on metabolic syndrome status: oneyear results of the PREDIMED randomized trial." Arch Intern Med 168 (22): 24492458.

Salas-Salvado, J., M. A. Martinez-Gonzalez, M. Bullo \& E. Ros (2011b). "The role of diet in the prevention of type 2 diabetes." Nutr Metab Cardiovasc Dis.

Sanchez-Tainta, A., R. Estruch, M. Bullo, D. Corella, E. Gomez-Gracia, M. Fiol, J. Algorta, M. I. Covas, J. Lapetra, I. Zazpe, V. Ruiz-Gutierrez, E. Ros \& M. A. Martinez-Gonzalez (2008). "Adherence to a Mediterranean-type diet and reduced prevalence of clustered cardiovascular risk factors in a cohort of 3,204 high-risk patients." Eur J Cardiovasc Prev Rehabil 15 (5): 589-593.

Sarwar, N., J. Danesh, G. Eiriksdottir, G. Sigurdsson, N. Wareham, S. Bingham, S. M. Boekholdt, K. T. Khaw \& V. Gudnason (2007). "Triglycerides and the risk of coronary heart disease: 10,158 incident cases among 262,525 participants in 29 Western prospective studies." Circulation 115 (4): 450-458.

Scarmeas, N., J. A. Luchsinger, Y. Stern, Y. Gu, J. He, C. DeCarli, T. Brown \& A. M. Brickman (2011). "Mediterranean diet and magnetic resonance imaging-assessed cerebrovascular disease." Ann Neurol 69 (2): 257-268.

Schini-Kerth, V. B., C. Auger, N. Etienne-Selloum \& T. Chataigneau (2010). "Polyphenolinduced endothelium-dependent relaxations role of NO and EDHF." Adv Pharmacol 60: 133-175.

Schroder, H., J. Marrugat, J. Vila, M. I. Covas \& R. Elosua (2004). "Adherence to the traditional mediterranean diet is inversely associated with body mass index and obesity in a spanish population." J Nutr 134 (12): 3355-3361.

Schwartz, G. J., J. Fu, G. Astarita, X. Li, S. Gaetani, P. Campolongo, V. Cuomo \& D. Piomelli (2008). "The lipid messenger OEA links dietary fat intake to satiety." Cell Metab 8 (4): 281-288.

Seo, T., W. S. Blaner \& R. J. Deckelbaum (2005). "Omega-3 fatty acids: molecular approaches to optimal biological outcomes." Curr Opin Lipidol 16 (1): 11-18.

Serra-Majem, L., B. Roman \& R. Estruch (2006). "Scientific evidence of interventions using the Mediterranean diet: a systematic review." Nutr Rev 64 (2 Pt 2): S27-47.

Shah, M., B. Adams-Huet \& A. Garg (2007). "Effect of high-carbohydrate or high-cismonounsaturated fat diets on blood pressure: a meta-analysis of intervention trials." Am J Clin Nutr 85 (5): 1251-1256.

Shai, I., J. D. Spence, D. Schwarzfuchs, Y. Henkin, G. Parraga, A. Rudich, A. Fenster, C. Mallett, N. Liel-Cohen, A. Tirosh, A. Bolotin, J. Thiery, G. M. Fiedler, M. Bluher, M. 
Stumvoll \& M. J. Stampfer (2010). "Dietary intervention to reverse carotid atherosclerosis." Circulation 121 (10): 1200-1208.

Singh, I., M. Mok, A. M. Christensen, A. H. Turner \& J. A. Hawley (2008). "The effects of polyphenols in olive leaves on platelet function." Nutr Metab Cardiovasc Dis 18 (2): 127-132.

Sirtori, C. R., E. Tremoli, E. Gatti, G. Montanari, M. Sirtori, S. Colli, G. Gianfranceschi, P. Maderna, C. Z. Dentone, G. Testolin \& et al. (1986). "Controlled evaluation of fat intake in the Mediterranean diet: comparative activities of olive oil and corn oil on plasma lipids and platelets in high-risk patients." Am J Clin Nutr 44 (5): 635-642.

Slavka, G., T. Perkmann, H. Haslacher, S. Greisenegger, C. Marsik, O. F. Wagner \& G. Endler (2011). "Mean platelet volume may represent a predictive parameter for overall vascular mortality and ischemic heart disease." Arterioscler Thromb Vasc Biol 31 (5): 1215-1218.

Smith, R. D., C. N. Kelly, B. A. Fielding, D. Hauton, K. D. Silva, M. C. Nydahl, G. J. Miller \& C. M. Williams (2003). "Long-term monounsaturated fatty acid diets reduce platelet aggregation in healthy young subjects." Br J Nutr 90 (3): 597-606.

Sofi, F., R. Abbate, G. F. Gensini \& A. Casini (2010). "Accruing evidence about benefits of adherence to the Mediterranean diet on health: an updated systematic review and meta-analysis." Am J Clin Nutr.

Sofi, F., F. Cesari, R. Abbate, G. F. Gensini \& A. Casini (2008). "Adherence to Mediterranean diet and health status: meta-analysis." Bmj 337: a1344.

Solfrizzi, V., F. Panza, V. Frisardi, D. Seripa, G. Logroscino, B. P. Imbimbo \& A. Pilotto (2011). "Diet and Alzheimer's disease risk factors or prevention: the current evidence." Expert Rev Neurother 11 (5): 677-708.

Spence, J. D. (2010). "Secondary stroke prevention." Nat Rev Neurol 6 (9): 477-486.

Stock, J. (2011). "Mediterranean diet for combating the metabolic syndrome." Atherosclerosis.

Tangney, C. C., M. J. Kwasny, H. Li, R. S. Wilson, D. A. Evans \& M. C. Morris (2011). "Adherence to a Mediterranean-type dietary pattern and cognitive decline in a community population." Am J Clin Nutr 93 (3): 601-607.

Tekbas, E., A. F. Kara, Z. Ariturk, H. Cil, Y. Islamoglu, M. A. Elbey, S. Soydinc \& M. S. Ulgen (2011). "Mean platelet volume in predicting short- and long-term morbidity and mortality in patients with or without ST-segment elevation myocardial infarction." Scand J Clin Lab Invest.

Temme, E. H., R. P. Mensink \& G. Hornstra (1999). "Effects of diets enriched in lauric, palmitic or oleic acids on blood coagulation and fibrinolysis." Thromb Haemost 81 (2): 259-263.

Tortosa, A., M. Bes-Rastrollo, A. Sanchez-Villegas, F. J. Basterra-Gortari, J. M. NunezCordoba \& M. A. Martinez-Gonzalez (2007). "Mediterranean diet inversely associated with the incidence of metabolic syndrome: the SUN prospective cohort." Diabetes Care 30 (11): 2957-2959.

Tozzi Ciancarelli, M. G., C. Di Massimo, D. De Amicis, I. Ciancarelli \& A. Carolei (2011). "Moderate consumption of red wine and human platelet responsiveness." Thromb Res 128 (2): 124-129.

Trichopoulou, A., A. Naska, P. Orfanos \& D. Trichopoulos (2005). "Mediterranean diet in relation to body mass index and waist-to-hip ratio: the Greek European Prospective Investigation into Cancer and Nutrition Study." Am J Clin Nutr 82 (5): 935-940. 
Tripoli, E., M. Giammanco, G. Tabacchi, D. Di Majo, S. Giammanco \& M. La Guardia (2005). "The phenolic compounds of olive oil: structure, biological activity and beneficial effects on human health." Nutr Res Rev 18: 98-112.

Turpeinen, A. M. \& M. Mutanen (1999). "Similar effects of diets high in oleic or linoleic acids on coagulation and fibrinolytic factors in healthy humans." Nutr Metab Cardiovasc Dis 9 (2): 65-72.

van den Brandt, P. A. (2011). "The impact of a Mediterranean diet and healthy lifestyle on premature mortality in men and women." Am J Clin Nutr.

van Wijk, D. F., E. S. Stroes \& J. J. Kastelein (2009). "Lipid measures and cardiovascular disease prediction." Dis Markers 26 (5-6): 209-216.

Varbo, A., B. G. Nordestgaard, A. Tybjaerg-Hansen, P. Schnohr, G. B. Jensen \& M. Benn (2011). "Nonfasting triglycerides, cholesterol, and ischemic stroke in the general population." Ann Neurol 69 (4): 628-634.

Vardavas, C. I., A. D. Flouris, A. Tsatsakis, A. G. Kafatos \& W. H. Saris (2011). "Does adherence to the Mediterranean diet have a protective effect against active and passive smoking?" Public Health 125 (3): 121-128.

Visioli, F., D. Caruso, S. Grande, R. Bosisio, M. Villa, G. Galli, C. Sirtori \& C. Galli (2005). "Virgin Olive Oil Study (VOLOS): vasoprotective potential of extra virgin olive oil in mildly dyslipidemic patients." Eur J Nutr 44 (2): 121-127.

Visioli, F. \& C. Galli (1998). "The effect of minor constituents of olive oil on cardiovascular disease: new findings." Nutr Rev 56 (5 Pt 1): 142-147.

Wang, R. T., Y. Li, X. Y. Zhu \& Y. N. Zhang (2011). "Increased mean platelet volume is associated with arterial stiffness." Platelets 22 (6): 447-451.

Willett, W. C. (2006). "The Mediterranean diet: science and practice." Public Health Nutr 9 (1A): 105-110.

Williams, C. M. (2001). "Beneficial nutritional properties of olive oil: implications for postprandial lipoproteins and factor VII." Nutr Metab Cardiovasc Dis 11 (4 Suppl): $51-56$.

Yubero-Serrano, E. M., A. Garcia-Rios, J. Delgado-Lista, N. Delgado-Casado, P. PerezMartinez, F. Rodriguez-Cantalejo, F. Fuentes, C. Cruz-Teno, I. Tunez, I. TassetCuevas, F. J. Tinahones, F. Perez-Jimenez \& J. Lopez-Miranda (2011). "Postprandial effects of the Mediterranean diet on oxidant and antioxidant status in elderly men and women." J Am Geriatr Soc 59 (5): 938-940. 




\author{
Cardiovascular Risk Factors \\ Edited by Prof. Armen Gasparyan
}

ISBN 978-953-51-0240-3

Hard cover, 498 pages

Publisher InTech

Published online 14, March, 2012

Published in print edition March, 2012

Cardiovascular risk factors contribute to the development of cardiovascular disease from early life. It is thus crucial to implement preventive strategies addressing the burden of cardiovascular disease as early as possible. A multidisciplinary approach to the risk estimation and prevention of vascular events should be adopted at each level of health care, starting from the setting of perinatology. Recent decades have been marked with major advances in this field, with the emergence of a variety of new inflammatory and immunemediated markers of heightened cardiovascular risk in particular. The current book reflects some of the emerging concepts in cardiovascular pathophysiology and the shifting paradigm of cardiovascular risk estimation. It comprehensively covers primary and secondary preventive measures targeted at different age and gender groups. Attention is paid to inflammatory and metabolic markers of vascular damage and to the assessment of vascular function by noninvasive standardized ultrasound techniques. This is a must-read book for all health professionals and researchers tackling the issue of cardiovascular burden at individual and community level. It can also serve as a didactic source for postgraduate medical students.

\title{
How to reference
}

In order to correctly reference this scholarly work, feel free to copy and paste the following:

Javier Delgado-Lista, Ana I. Perez-Caballero, Pablo Perez-Martinez, Antonio Garcia-Rios, Jose Lopez-Miranda and Francisco Perez-Jimenez (2012). Mediterranean Diet and Cardiovascular Risk, Cardiovascular Risk Factors, Prof. Armen Gasparyan (Ed.), ISBN: 978-953-51-0240-3, InTech, Available from: http://www.intechopen.com/books/cardiovascular-risk-factors/mediterranean-diet-and-cardiovascular-risk

\section{INTECH}

open science | open minds

\section{InTech Europe}

University Campus STeP Ri

Slavka Krautzeka 83/A

51000 Rijeka, Croatia

Phone: +385 (51) 770447

Fax: +385 (51) 686166

www.intechopen.com

\section{InTech China}

Unit 405, Office Block, Hotel Equatorial Shanghai

No.65, Yan An Road (West), Shanghai, 200040, China 中国上海市延安西路65号上海国际贵都大饭店办公楼 405 单元

Phone: +86-21-62489820

Fax: $+86-21-62489821$ 
(C) 2012 The Author(s). Licensee IntechOpen. This is an open access article distributed under the terms of the Creative Commons Attribution 3.0 License, which permits unrestricted use, distribution, and reproduction in any medium, provided the original work is properly cited. 